\title{
Significant Diseases of Two Very Aged Red Foxes (Vulpes vulpes, Demarest 1820)
}

\section{Dennis Lawler ${ }^{\mathrm{a}, \mathrm{d}, \mathrm{e}, \mathrm{f}^{*}, \text { Julia Becker }}{ }^{\mathrm{b}}$, Patricia Goodman ${ }^{\mathrm{c}}$, Richard Evans ${ }^{\mathrm{d}}$, Luci Kohn ${ }^{\mathrm{e}}$}

\author{
allinois State Museum, 1011 E. Ash St., Springfield IL 62703 USA \\ bTippecanoe Animal Hospital, 3818 State Rd. 38 E, Lafayette, Indiana 47905 USA \\ 'Wolf Park, 4004 E 800 N, Battle Ground, Indiana 47920 USA \\ dPacific Marine Mammal Center, 20612 Laguna Canyon Rd., Laguna Beach, CA 92561 \\ USA \\ eDepartment of Biology, Southern Illinois University, Edwardsville, IL 62025 USA \\ fCenter for American Archaeology, Rt. 100, Kampsville IL USA 62053
}

With 5 figures \& I table $\quad$ Received April, accepted for publication June 2017

\section{Abstract}

Wild mammal survival rarely approaches ages that are possible in genomic terms. Thus, sheltered environments present unique opportunities to study wild mammal aging and compare aging-related disorders to those of similar domestic animals. We evaluated two aged red fox vixens that had lived in a park setting where they were not caged, and were provided an environment that reflected a natural setting as closely as possible, while providing for proper nutrition and health care. During their $14^{\text {th }}$ year, both foxes developed symptoms suggesting orthopedic and renal deterioration. After diagnosis, monitoring, and humane euthanasia, postmortem evaluation revealed degenerative joint and renal disease, each closely resembling organ-specific pathology of aged domestic dogs.

Based on evaluation of these foxes and other recent reports, we hypothesize that underlying mechanisms for late life pathological changes reflect broadly and deeply conserved response capacities and not artificial environments, provided that shelter, nutrition, and health care are adequate to minimize stochastic mortality that prevails in the wild.

Keywords: Aging, hip, kidney, osteoarthritis, red fox, shoulder, Vulpes vulpes 


\section{Introduction}

\section{Background}

The red fox (Vulpes vulpes [fulva], Demarest 1820) is highly successful, having the largest global distribution of any extant terrestrial carnivore (Henry 1996; Cypher 2003). Its dispersal patterns appear related to population density, interspecies competition, and habitat change (Allen and Seargeant 1999). Adult size is variable with mature body weight 3.0-8.0 kilograms, but on average it is the largest among North American foxes (Cypher 2003). Longevity of 8.6 years in the wild has been reported for a tagged red fox, but in free-living populations, survival as long as 6 years is uncommon (Allen and Seargeant 1999; Storm et al.1976; Tuller 1983). Since survival in the wild rarely approaches true species limits of longevity, elucidating the aging process in wild species remains a very difficult task. Considering available observational methods, establishing control populations of "normal" free-roaming subjects for comparative studies is nearly impossible because of the natural delay between biological onset of many late life diseases and onset of overt symptoms, and because of the ability of wild mammals to disguise pain and symptoms of organ disease. Thus, the most pressing need is to report all species-related aging observations to build a database from which to clarify late life diseases in wild mammals. In this regard, we report examination of shoulder and hip joints, and kidneys, of two red fox vixens that were euthanized during their $14^{\text {th }}$ year because of orthopedic and renal disease. The observations, along with other recent studies, contribute to expanding our understanding of the mammalian aging process.

\section{Life histories}

The two females (vixens), named Devon and Ember (not siblings), were born in the spring of 2000. They were habitat-reared and maintained together. They were fed a natural diet consisting of deer meat and small rodents, occasional rabbits, fruits and vegetables, and they regularly caught small rodents and insects such as cicadas. They resided at Wolf Park, Battle Ground IN, in an enclosure measuring $60 \times 40$ feet, with ladders and decks for climbing and jumping, thus allowing natural fox behavior. They were vaccinated for rabies, distemper, leptospirosis, parvovirus, coronavirus, adenovirus, parainfluenza virus, and lyme disease, and were monitored daily. Health history of each fox was unremarkable until late life. 
A few weeks prior to humane euthanasia in their $14^{\text {th }}$ year, both foxes exhibited signs of reduced activity and declining range of joint motion, resulting in end-of-life maintenance indoors. Biochemical evaluation indicated progressive renal failure in both foxes (Table 1). Following humane euthanasia, postmortem examinations were done by the attending veterinarian as a part of normal health care practices. The foxes were not part of a research study, and Institutional Animal Care and Use Committee clearance was not required.

\section{Materials and Methods}

\section{Tissue harvest and processing}

Gross postmortem examination of both foxes revealed pale yellow, rough-surfaced kidneys that were not contracted or nodular. The left kidney from Ember was preserved in formalin and sent to the consulting pathologist for routine histological evaluation, to parallel routine veterinary clinical practices.

Harvest of shoulder and hip joints was done en bloc, followed by freezing at $-4^{\circ} \mathrm{C}$. Other remains were buried with ceremony, according to Park practices. The frozen bone specimens were transferred to the Illinois State Museum Research and Collections Center, Springfield IL. Bone processing was continued by trimming soft tissue and incubating in hot

J. Vet. Anat. water $\left(40-45^{\circ} \mathrm{C}\right)$ to macerate remaining non-ossified tissue by bacterial action, with filtering and water replacement as needed. Following several weeks' incubation, soaking in $15-20 \%$ ammonia solution promoted further removal of fat from bone. A final brushing step in detergent was done to remove tightly adhered exuded fat. Following clearing, bones were rinsed in tap water and dried. Evaluation of joint components included scapular, humeral, acetabular, and femoral articular surfaces and margins, and periarticular structure. Lumbar vertebrae 5-7 and the sacrum were available from Ember. All harvested bone components were photogra-phed and descriptions recorded.

\section{Results}

\section{Renal disease}

Renal histopathology (Ember) yielded diffuse, moderate-severe, chronic, glomerular and tubular, calcinosis and interstitial fibrosis (Table 1, Fig 1).

\section{Scapular glenoid}

Glenoid fossae were bordered or impinged by encircling articular margin / periarticular prominence, rimming, or osteophytes that were severe in Devon and mild in Ember. Glenoid articular surfaces (Devon) revealed circular caudolateral features $(3 \mathrm{~mm}$, left side affected more severely) characterized by loss of articular 
bone and exposure of thickened underlying trabeculae (Fig 2). Ember was affected similarly but less severely. Both foxes also revealed right glenoid pinpoint depression caudolateral (Devon) or craniocentral (Ember), consistent with focal ossification failure.

\section{Proximal humerus}

Proximal humeral articulations were bordered or impinged by encircling articular margin/periarticular prominence, rimming, or osteophytes. The features were severe in Devon (Fig 3 ) and milder in Ember. Both intertubercular (bicipital) grooves revealed severe osteophytes in Devon (Fig 4), while similar lesions in Ember were less severe. The latter features are compatible with degrees of co-morbid biceps tendonitis. Ember also revealed a $1 \times 3 \mathrm{~mm}$ mid-lateral articular surface defect on the left humerus.

\section{Acetabulum}

Acetabular fossae of both foxes revealed bone formation suggesting enthesiophytes. The new bone formation was more severe in Devon, impinging the dorsomedial articular surface bilaterally (Fig 5). The medial acetabular articular margins were prominent in both foxes, while Devon had small osteophytes at each caudal acetabular margin.
The dorsal femoral necks revealed very mild filling with new bone (Devon), and prominent femoral head articular margins (Devon and Ember, with greater severity in Devon). Ember had severe spondylosis deformans of cranial and caudal aspects of lumbar vertebrae 6 and 7 , and cranial sacrum.

\section{Discussion}

\section{Behaviors and osteoarthritis}

The red fox hunts small prey by pouncing and pinning the prey with its forefeet, killing it with a bite. Suddenly attacking small prey from brush cover also is a common behavior. Somewhat larger prey (rabbits) are stalked and attacked with jumping or sprinting behaviors (Scott 1943). Other normal fox behaviors include brisk walk as the normal gait; trotting up to several kilometers and jumping to about 4 meters; occasional swimming or climbing; and active defense of a home range (Pasitschniak-Arts and Pasitschniak-Arts 1996). At Wolf Park, very similar behaviors (especially in young foxes) include jumping from heights of 1.3-2.0 m; climbing fences, play-ladders, or trees; pouncing on insects such as cicadas; and playing on a trampoline.

\section{Proximal femur and spine}


Given an active lifestyle and carnivorous behaviors, significant prevalence of arthropathy might be expected in the uncommon event that a free-living fox survives to advanced age. Obesity is a well-known risk for osteoarthritis in several mammalian species (Anderson and Felson 1988; Davis et al, 1988; van Saase et al, 1988; Bendele and Hulman 1991; Popovitch et al, 1995; Lawler et al, 2008), but obesity is unusual in wild canids. In the foxes we evaluated, only seasonally-expected fluctuations in body condition were observed, without obesity at any time during life. Thus, environmental and nutritional influences seem insufficient to explain the disease observations. The latter is interesting, considering the similarities to the parallel conditions among elderly domestic dogs.

\section{Renal disease}

The similarity of the fox renal morphology to late-life renal disease in domestic dogs prompts hypotheses that (a) soft organ diseases of aged Canidae may be more universal consequences of simple chronology than has been supposed; and (b) immediate environments may be correspondingly less influential provided that nutrition, shelter, and health care are adequate. Additional late life biochemical studies of wild canids that live to species-possible ages should be conducted and published, to explore more completely the chronological prevalence of diseases across related individuals in non-domestic populations.

\section{Joint disease - shoulder}

In a cross-sectional study of 88 randomly-selected domestic dogs (mean age 8.2 years, range 1-12), shoulder radiography revealed primary age-related osteoarthritis in $31 \%$ of the group (mean age 10.2 years)(Ljunggren and Olsson 1975). A cross-sectional study of skeletal remains of 16 adult raccoon dogs (Nyctereutes procyonoides) revealed $100 \%$ prevalence of the same glenoid features that were observed in the two vixens, with severity ranging from near-normal to mild osteoarthritis, while $81 \%$ of proximal humeral articulations also reflected the fox observations (Lawler et al, 2012). Recently, lesions of scapular glenoid articular cartilage were related spatially to underlying pathology of articular bone in 7 gray wolves (ages 519 years), and the nature and spatial distribution of the osteoarthritis changes were again the same as the foxes and raccoon dogs (Lawler et al, 2016).

A longitudinal study of 149 domestic dogs revealed $53 \%$ radiographic prevalence of age-related shoulder osteoarthritis at mean age 13.8 years 
(Morgan et al, 1987). In another longitudinal study, 43 Labrador retrievers had more radiographic shoulder osteoarthritis at age 8 years than elbows, hips, and stifles of the same dogs (Kealy et al, 2000).

\section{Joint disease - hip \& spine}

One left femoral head lesion (Devon) is compatible with an early circumferential femoral head osteophyte (Szabo et al, 2007). The red fox osteoarthritis-related pathology of acetabula and proximal femoral articulations mimic observations of domestic dogs (Lawler et al, 2008) and raccoon dogs (Lawler et al, 2012). A report of femoral head radiographic pathology in a gray wolf (Canis lupus lupus) described very similar features (Lawler and Evans 2016). The intraand extra-articular spatial locations of these features are consistent across canids examined to date, with the expected age-related variation in severity.

Spondylosis refers to osteophyte formation around cranial and/or caudal vertebral end plates, secondary to degenerative disease of the adjacent intervertebral disk (Morgan and Biery 1985). The intervertebral disk space may be narrowed and adjacent vertebrae become unstable, prompting osteophyte reaction. Older large domestic dogs develop spondylosis more frequently, but smaller dogs also are affected. Some affected dogs experience pain and difficult movement, while others remain relatively asymptomatic (Prada 1993). We are not aware that this pathology has been investigated in red foxes, but the strong similarity between fox and other canid features again is striking.

Studies of domestic dogs demonstrate that radiography significantly underestimates diarthrodial joint pathology (Morgan et al, 1987; Runge et al, 2008; Lawler and Evans 2016), and radiographic diagnosis of joint pathology in other canids introduces these same limitations (Lawler et al, 2016). We suggest that comparative joint biology studies of Canidae have been impeded by (a) limitations inherent in most imaging modalities; (b) hazards of anesthetizing wild animals for examination; (c) relative infrequency of highly detailed postmortem study of wild mammal diarthrodial joints.

\section{Integrative joint development and function}

Studies of morphological integration examine relationships among anatomical structures (Cheverud 1982, 1995, 1996). Common functional attributes, such as the shape of the proximal humerus and scapular glenoid fossa, lead to functional integra- 
tion with muscle actions that are necessary for proper function, implying common developmental influences during formation and growth (integration). These influences may be hormonal, or they may relate to interaction of developing tissues.

Integrated structures evolve together because of correlated inheritance and shared influence from natural selection. Functional and developmental morphological integration occur at the individual level, and evolutionary integration occurs at the population level (Cheverud 1982, 1995, 1996).

Integrated traits are expected to exhibit a significant correlation among traits within the anatomical module, based on their shared influences (Cheverud 1982, 1995, 1996; Hallgrimsson et al, 2002). Morphological integration studies of mammalian scapulae have examined the developmental, functional, and evolutionary structure of the scapular glenoid and blade (Young 2004, 2006, 2008). Scapula studies of seven primate species (Young 2004) and six mustelid species (Norman 2016) identified significant integration within the glenoid, as well as within the blade and acromion. Locomotion influences on integration were observed in 17 primate species (Young 2008). Developmental influences of the Hoxc6 gene on glenoid
(Olivier et al, 1990); Emx2 gene influencing the scapula blade (Pellegrini et al, 2001); and Pax1 gene influencing the scapular blade and acromion (Timmons et al, 1994; Wilm et al, 1994), help to elucidate the genomic integration of these developmental and functional regions. It follows that associated soft tissue structures should be governed under common developmental and functional influences.

Further evaluations of integrated diarthrodial joint components, based on phylogeny and functional morphology, should further clarify why degenerative joint pathology tends to occur at nearly identical foci within the same joint, across species.

\section{Conclusions}

It is clear that aging-related osteoarthritis is not unique to the domestic dog and occurs among other Canidae, in similar joint-specific spatial patterns. Primary influences on expression of late life diseases among canids appear to reflect (a) speciesrelated achievable longevity; (b) the balance among disease onset and the subsequent time that symptoms develop to be observed; and (c) genome-mediated responses to insults that appear to be conserved phylogenetically. 


\section{Acknowledgements}

Specimens and histories were provided by Wolf Park (Battle Ground, Indiana). The Illinois State Museum research and Collections Center (Springfield IL) provided specimenprocessing facilities for this work. This work was conducted pro bono and was unfunded.

\section{References}

Allen, S.H., Sargeant, A.B. (1999): Dispersal patterns of red foxes relative to population density. Journal of Wildlife Management 57: 526-533.

Anderson, J.J., Felson, D.T. (1988): Factors associated with osteoarthritis of the knee in the first national health and nutrition examination survey (Hanes I). American Journal of Epidemiology 128: 179189.

Bendele, A.M., Hulman, F.J. (1991): Effects of body weight restriction on the development of and progression of spontaneous osteoarthritis in guinea pigs. Arthritis and Rheumatism 34: 1180-1184.

Cheverud, J.M. (1982): Phenotypic, genetic and environmental morphological integration in the cranium. Evolution 36: 499-516.

Cheverud, J.M. (1995): Morphological integration in the saddle-back tamarin (Saguinus fuscicollis) cranium. American Naturalist 145: 6389.

Cheverud, J.M. (1996): Developmental integration and the evolution of pleiotropy. American Zoologist 36: 44-50.

Cypher, B.L. (2003): Foxes. In: Feldhamer, G.A., Thompson, B.C., Chapman, J.A. (eds.). Wild Mammals of North America, $2^{\text {nd }}$ edition. Johns Hopkins University Press, Baltimore, pp. 511-546.

Davis, M.A., Ettinger, W.H., Neuhaus, J.M., Hauck, W.W. (1988): Sex differences in osteoarthritis of the knee. American Journal of Epidemiology 127: 1019-1030.

Hallgrimsson, B., Willmore, K., Hall, B.K. (2002): Canalization, developmental stability and morphological integration in primate limbs. Yearbook of Physical Anthropology 45: 131-158.

Henry, J.D. (1996): Foxes: Living on the Edge. In: Northwood Wildlife Series. Minocqua, Wisconsin.

Kealy, R.D., Lawler, D.F., Ballam, J.M., Lust, G., Biery, D.N., Smith, G.K., Mantz, S.L. (2000): Evaluation of the effect of limited food consump- 
tion on radiographic evidence of osteoarthritis in dogs. Journal of the American Veterinary Medical Association 217: 1678-1680.

Lawler, D., Becker, J., Reetz, J., Goodman, P., Evans, R., Rubin, D., Tangredi, B., Widga, C., Sackman, J., Martin, T., Kohn, L., Smith, G. (2016): Pathology of grey wolf shoulders: Lessons in species and aging. Anatomical Review doi: 10.1002/ar.23380

Lawler, D.F., Larson, B.T., Ballam, J.M., Smith, G.K., Biery, D.N., Evans, R.H., Greeley, E.H., Segre, M., Stowe, H.D., Kealy, R.D. (2008): Diet restriction and aging in the dog. Summary of major observations over two decades. British Journal of Nutrition 99:

793-805.

Lawler, D.F., Evans, R.H., Nieminen, P., Mustonen, A.-M., Smith, G.K. (2012): Lessons from a non-domestic canid: joint disease in captive raccoon dogs (Nyctereutes procyonoides). Veterinaria Italiana 48(4): 367-378.

Lawler, D.F., Evans, R.H. (2016): Evaluation of femoral head and neck new bone from a grey wolf (Canis lupus lupus): When is it pathology? Journal of Veterinary Anatomy 9(1): 9-46.
Ljunggren, G., Olsson, S.-E., (1975): Osteoarthritis of the shoulder and elbow joints in dogs: a pathologic and radiographic study of necropsy material. Journal of the American Veterinary Radiological Society 16 : 33-38.

Morgan, J.P., Pool, R.R., Miyabayashi, T. (1987): Primary degenerative joint disease of the shoulder in a colony of beagles. Journal of the American Veterinary Medical Association 190: 531-540.

Morgan, J.P., Biery, D.N. (1985): Spondylosis deformans. In: Newton, C.D., Nunamaker, D.H. (eds.). Textbook of Small Animal Orthopedics. JB Lippincott, Philadelphia. pp. 773788.

Norman, S. (2016): Morphometric analysis of scapula morphology within the Mustelidae family. Masters Thesis. Southern Illinois University, Edwardsville IL USA.

Olivier, G., de Robertis, E.M., Wolpert, L., Tickle, C. (1990): Expression of a homeobox gene in the chick wing bud following application of retinoic acid and grafts of polarizing region tissue. EMBO Journal 9: 3093-3099. 
Pasitschniak-Arts, S., Pasitschniak-Arts, M. (1996): Vulpes vulpes. In: American Society of Mammalogists: Mammalian Species. No. 537: 1-11.

Pellegrini, M., Pantano, S., Fumi, M.P., Lucchini, F., Forabosco, A. (2001): Agenesis of the scapula in Emx2 homozygous mutants. Developmental Biology 232: 149-156.

Popovitch, C.A., Smith, G.K., Gregor, T.P., Shofer, F.S. (1995): Comparison of susceptibility to hip dysplasia between Rottweilers and German Shepherd dogs. Journal of American Veterinary Medical Association 206: 648-650.

Prada, R. (1993): Cauda Equina Syndrome. In: Slatter, D. (ed.). Textbook of Small Animal Surgery, $2^{\text {nd }}$ edition, Volume 1. WB Saunders, Philadelphia. pp. 1094-1105.

Runge, J.J., Biery, D.N., Lawler, D.F., Gregor, T.P., Evans, R.H., Kealy, R.D., Szabo, S.D., Smith, G.K. (2008): The effects of lifetime food restriction on the development of osteoarthritis in the canine shoulder. Veterinary Surgery 37: 102-107.

Scott, T.G. (1943): Some food coactions of the northern plains red fox. Ecological Monographs 13: 427-473.
Storm, G.L., Andrews, R.D., Phillips, R.L., Bishop, R.A., Siniff, D.B., Tester, J.R. (1976): Morphology, reproduction, dispersal and mortality of midwestern red fox populations. Wildlife Monographs 49: 1-82.

Szabo, S.D., Biery, D.N., Lawler, D.F., Shofer, F.S., Powers, M.Y., Kealy, R.D., Smith, G.K. (2007): Evaluation of a circumferential femoral head osteophyte as an early indicator of osteoarthritis characteristic of canine hip dysplasia in dogs. Journal of the American Veterinary Medical Association 231(6): 889-892.

Timmons, P.M., Wallin, J., Rigby, P.W., Balling, R. (1994): Expression and function of Pax1 during development of the pectoral girdle. Development 120: 2773-2785.

Tullar, B.F., Jr. (1983): An unusually long-lived red fox. New York Fish and Game Journal 30: 227.

van Saase, J.L., Vandenbroucke, J.P., van Romunde, L.K.J., Valkenburg, H.A. (1988): Osteoarthritis and obesity in the general population. A relationship calling for an explanation. Journal of Rheumatology 15: 1152-1158.

Young, N. (2004): Modularity and integration in the Hominoid scapula. Journal of Experimental Zoology 
(Molecular Development and Evolution) 302B: 226-240.

Young, N. (2006): Function, ontogeny and canalization of shape variance in the primate scapula. Journal of Anatomy 209: 623-636.

Young, N. (2008): A comparison of the ontogeny of shape variation in the anthropoid scapula: functional and phylogenetic signal. American Journal of Physical Anthropology 136: 247-264.
Wilm, B., Dahl, E., Peters, H., Balling, R., Imai, K. (1994): Targeted disruption of Pax 1 defines its null phenotype and proves haploinsufficiency. Proceedings of the National Academy of Sciences USA 95: 86928697.

\section{Corresponding author:}

Dennis Lawler Illinois State Museum, 1011 E. Ash St., Springfield IL 62703 USA dlawler11@yahoo.com

Table (1): Biochemical documentation of progressive renal disease in two elderly female Vulpes vulpes

\section{Ember}

\begin{tabular}{lccccc} 
& Urea nitrogen $(\mathrm{mg} / \mathrm{dl})$ & & Creatinine $(\mathrm{mg} / \mathrm{dl})$ & Phosphorus $(\mathrm{mg} / \mathrm{dl})$ & Hematocrit (\%) \\
\cline { 2 - 3 } $8 / 29 / 2014$ & 222 & 4.7 & 16.5 & 18 \\
$7 / 23 / 2014$ & 201 & 5.3 & 13.4 & 30 \\
$6 / 14 / 2014$ & 154 & 5.0 & & 35 \\
$5 / 28 / 2014$ & 136 & 5.0 & & 11.7 & 21 \\
$5 / 15 / 2014$ & 149 & 4.6 & & 34 \\
$5 / 01 / 2013$ & 68 & 1.7 & & 48 \\
$7 / 11 / 2012$ & 64 & 1.1 & 3.9 & 48 \\
$2 / 27 / 2011$ & 59 & 1.0 & & 46 \\
$1 / 30 / 2010$ & 26 & 0.6 & & 2.6 & 47
\end{tabular}

Devon

\section{$7 / 22 / 14$}

$6 / 14 / 14$

$5 / 15 / 14$

$9 / 11 / 13$

$5 / 01 / 13$

$7 / 11 / 12$

$7 / 27 / 11$

$3 / 05 / 11$

$8 / 24 / 10$

Urea nitrogen (mg/dl) Creatinine (mg/dl) Phosphorus (mg/dl) Hematocrit (\%)

$\begin{array}{rl}195 & 7.5 \\ 162 & 5.3 \\ 182 & 4.7 \\ 83 & 1.3 \\ 65 & 0.8 \\ 48 & 0.9 \\ 46 & 0.7 \\ 32 & 0.7 \\ 48 & 0.7\end{array}$

13.9

28

5.3

4.7

1.3

0.8

0.9

0.7

0.7

0.7
36

39

39

49

43

46

57

37 


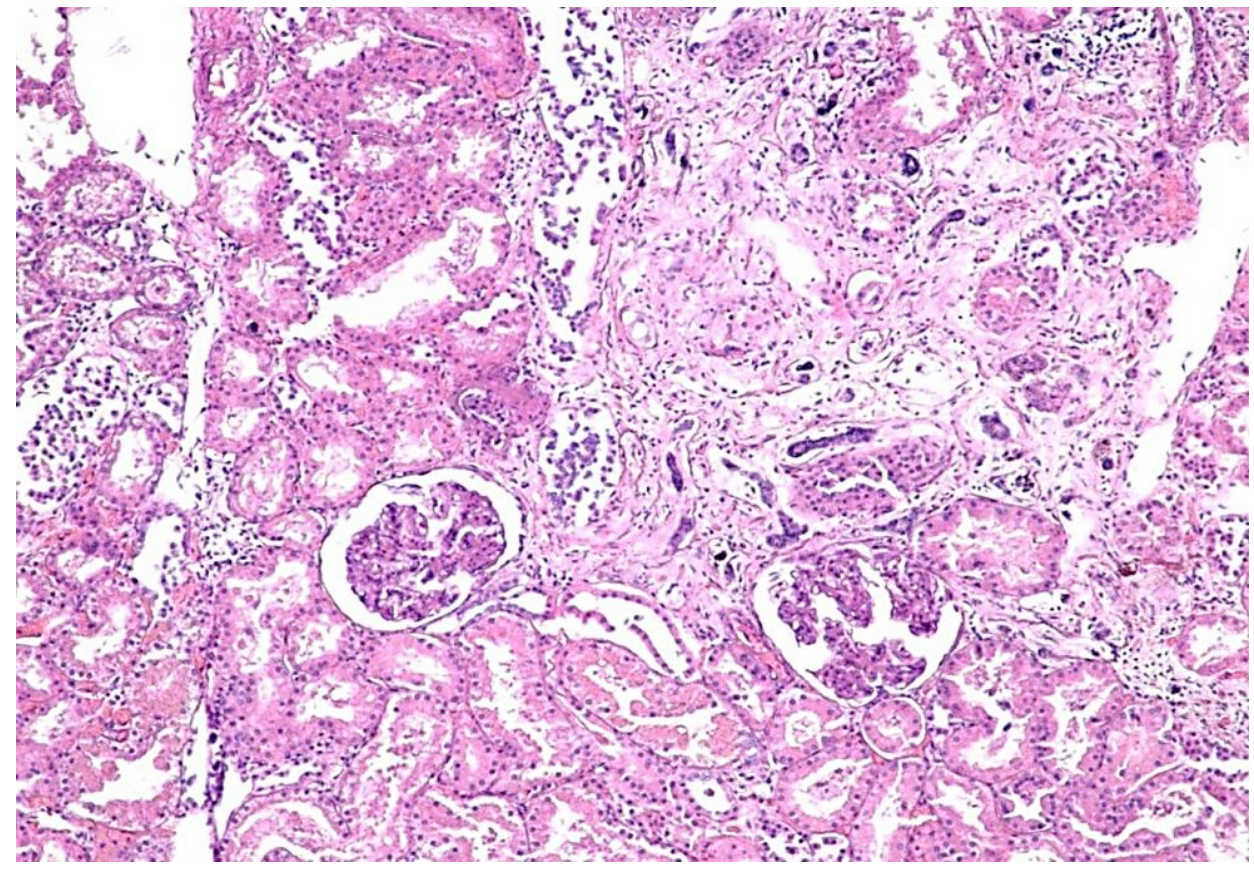

Fig (1): Ember, left kidney. Nephropathy, glomerular and tubular, dystrophic with calcinosis, chronic, moderate-severe, diffuse (H\&E).

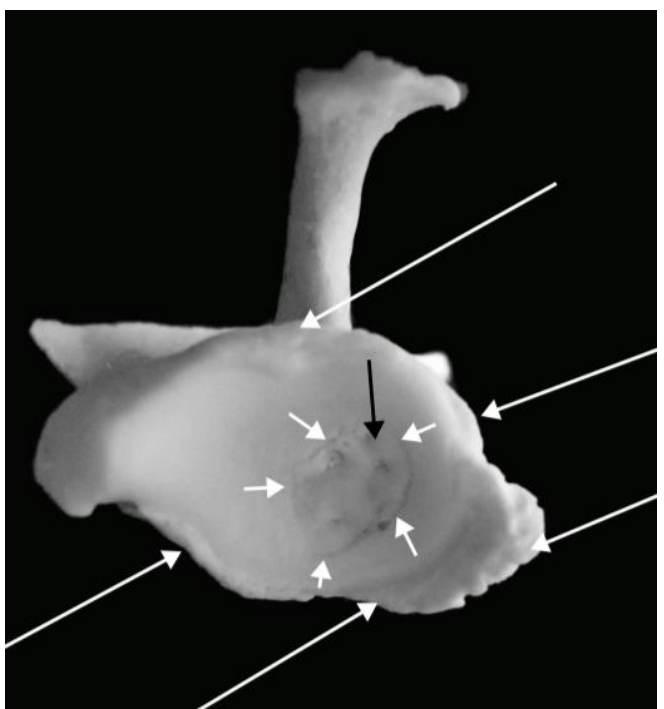

Fig (2): Devon, left scapula glenoid cavity. Severe encircling osteophytes (long white arrows); Bone loss mid-caudal fossa (short white arrows); Exposed thickened subarticular trabeculae (black arrow) 


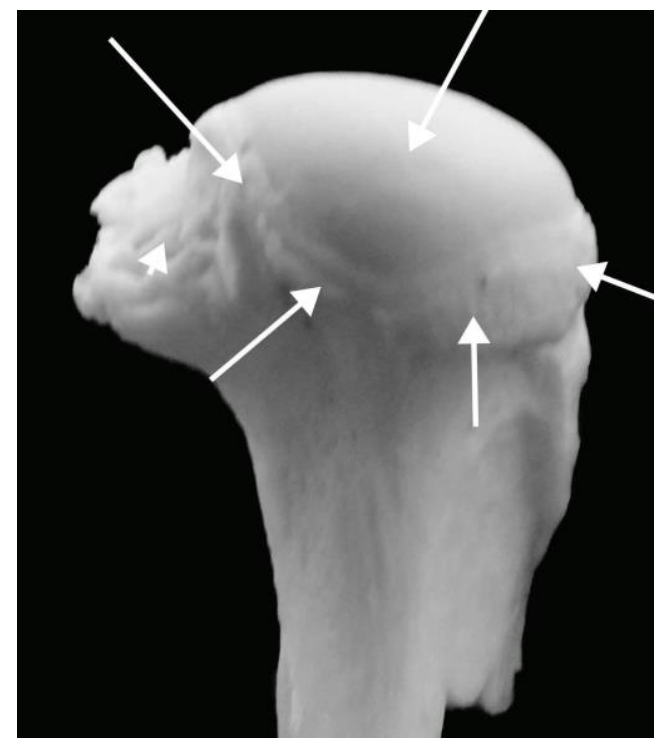

Fig (3): Devon, right proximal humerus, caudolateral view. Normal caudolateral articular surface (long white arrow); Severe encircling articular margin \& periarticular osteophytes impinging margin of articular surface (short white arrows); osteophytes on lesser tubercle (white arrowhead).

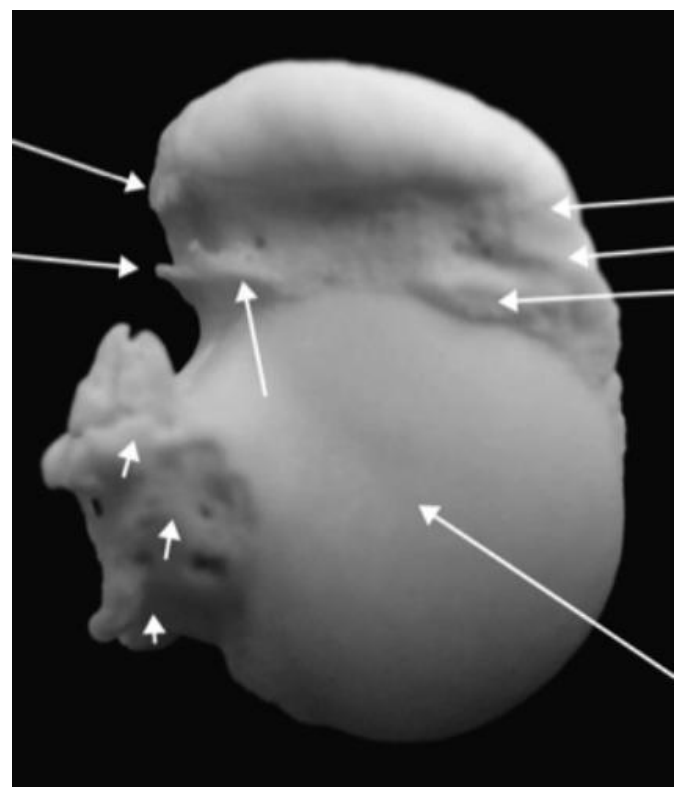

Fig (4): Devon, right proximal humerus, articular surface, dorsal view. Normal articular surface (long white arrow); Osteophytes on lesser tubercle (white arrowheads); Severe osteophytes medial \&lateral margin \& floor of intertubercular (bicipital) groove (short white arrows). 


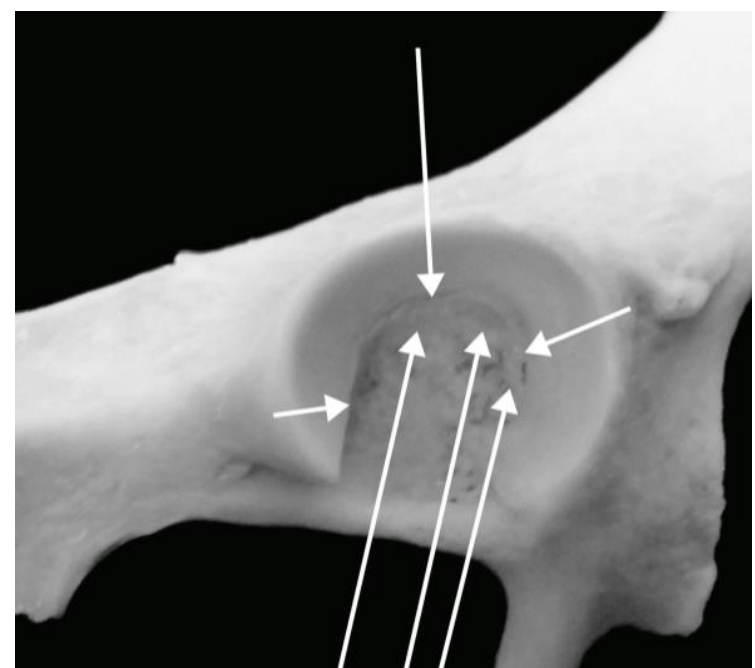

Fig (5): Devon, right acetabulum, lateral view. Severe new bone craniodorsal fossa, probable enthesiophytes (long white arrows); Impinging of medial articular surface (medium arrow); Prominent medial articular margin (short white arrows). 